\title{
Can spring lime applications help prevent damaging black beetle populations?
}

\author{
P.J. Gerard and D.J. Wilson
}

AgResearch, Ruakura Research Centre, Private Bag 3123, Hamilton, New Zealand

Corresponding author: pip.gerard@agresearch.co.nz

Black beetle (Heteronychus arator) attacks pasture grasses in the northern North Island and with warming temperatures, the beetle has extended its range and damage has become more prevalent. On-farm investigations into prevention of damaging populations suggested that black beetle density was inversely related to soil $\mathrm{pH}$. Furthermore, laboratory experiments indicated that first instar black beetle larval survival declined with increasing soil pH. A replicated block experiment in 2013-2015 on two farms with two sites/farm investigated late spring agricultural lime applications at the rate of 5 tonne/ha on summer black beetle populations. Over both summers, there was an overall significant reduction in black beetle populations in the lime treatments compared to the untreated plots with peat soil but no overall impact on the farm with ash soil. The effect appeared most pronounced in December when the early instars were present. A larger trial with eight sites and using the same application rate commenced in 2015. Initial results confirmed previous findings and showed a $41 \%$ reduction in December populations and an inverse relationship between soil $\mathrm{pH}$ and black beetle abundance in dairy pastures in late summer/early autumn. The results suggested that a soil $\mathrm{pH}$ of about 6 will both help mitigate black beetle and optimise pasture vigour to withstand the pest. 